\title{
酸化チタニウムの熱化學（第二報） 熱化學的計算
}

(昭利十年三月九日受領＼cjkstart昭利十年六月廿五日印刷)

那妢信行

\section{I. 緒言}

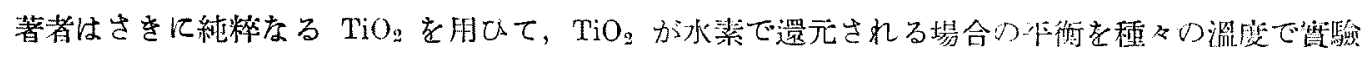

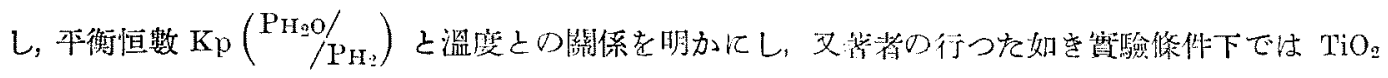

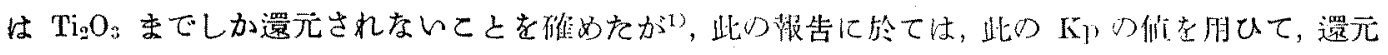

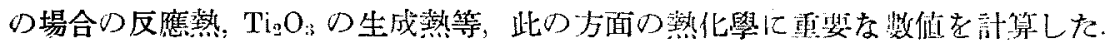

\section{II. 反應による熟含量の變化}

\section{1. 實驗温度範園內に於ける反應による熱含量の變化.}

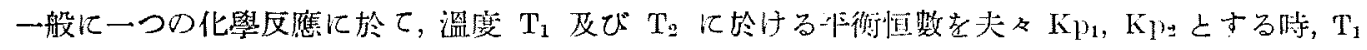

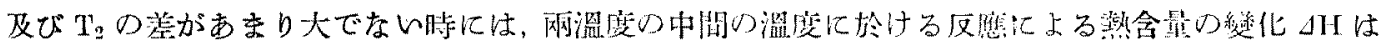
次の式によつて與へられる。郎占

依て

$$
\log \mathrm{K}_{\mathrm{P}_{2}}-\log \mathrm{K}_{\mathrm{p}_{1}}=\frac{\Delta \mathrm{H}}{2.3026 \mathrm{R}}\left(\frac{1}{\mathrm{~T}_{1}}-\frac{1}{\mathrm{~T}_{2}}\right)
$$

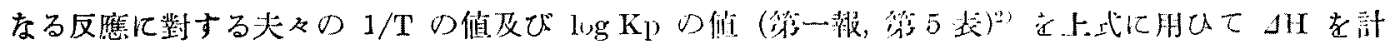

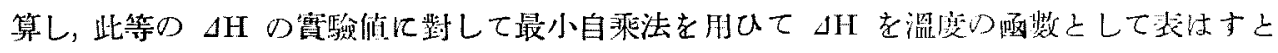

$$
\begin{array}{r}
\Delta \mathrm{H}_{\mathrm{r}}=-970+9.72 \mathrm{~T} \quad(\mathrm{cal}) \cdots \cdots \\
\mathrm{T}: 10+8 \sim 1256^{\circ} \mathrm{K}
\end{array}
$$

となる。

\section{2. $1256^{\circ} \mathrm{K}$ 以下の任意の温度に於ける反應による熱含量の變化}

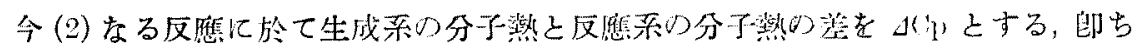

$$
\Delta \mathrm{Cp}_{\mathrm{P}}=\left(\mathrm{Cp}_{\mathrm{Ci}} \mathrm{O}_{3}+\mathrm{C}_{\mathrm{p} \mathrm{H}_{2} \mathrm{O}}\right)-\left(2 \mathrm{Cp}_{\mathrm{Ti}}+\mathrm{C}_{\mathrm{T}} \mathrm{H}_{2}\right)
$$

とすると

でる故

$$
\Delta \mathrm{H}_{\mathrm{T}}=\Delta \mathrm{H}_{0}+\int_{0}^{\mathrm{T}} \Delta \mathrm{T} \cdot \mathrm{dT}
$$

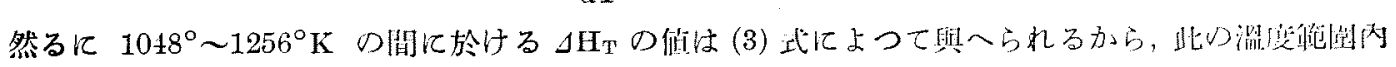
几於ては

$$
\Delta(\mathrm{c})=9.72 \mathrm{cal}
$$

次には $1043^{\circ} \mathrm{K}$ より低い溫度に於ける $1 \mathrm{Cp}$ を求女る。

1) 那預：本誌，56，(1935), 54:. 2) 本誌，56 (1935)，551. 
a. $\mathrm{TiO}_{\mathrm{g}}$ の分子烸.

TiO.の均分子熱としては L. F. Nilson 及び O. Petterson の测定 ${ }^{32}$ がある. 今此れを平均せ

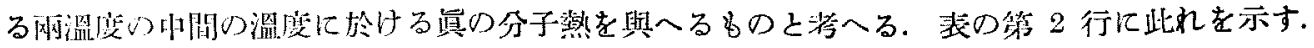

\begin{tabular}{|c|c|c|c|}
\hline 嘼废 ${ }^{\circ} \mathbf{K}$ & $\mathrm{Cpti}$ & $\mathrm{Cp}_{\mathrm{TiO}}$ & $\Delta \mathrm{Cp}$ \\
\hline 424 & 7.13 & 14.70 & - \\
\hline 498 & 7.77 & 15.30 & - \\
\hline 1152 & - & - & 9.72 \\
\hline
\end{tabular}

b. $\mathrm{Ti}_{2} \mathrm{O}_{3}$ の分子熟.

此の分子熱の實测低は皆無である. しかし乍ら下記の $4 \mathrm{Cp}$ の式にてわかる如く計算に必要な項は $\left(\mathrm{CpTi}_{2} \mathrm{O}_{3}-2 \mathrm{CpTiO}_{2}\right)$ であるから，今若し Kopp-Neumann の法则を䏳ひるすると， $\mathrm{R}_{2} \mathrm{O}_{3}$ 型の金屬 酸化物に䠌しては酸絜の見かけの原子熱は $4.8, \mathrm{RO}_{2}$ 型のそれは $3.9^{43}$ なる故

$\mathrm{CpTi}_{2} \mathrm{O}_{3}-2 \mathrm{C}_{\mathrm{pTiO}_{2}}=2 \mathrm{CpTi}_{\mathrm{Ti}}+4.8 \times 3-\left(2 \mathrm{Cp}_{\mathrm{Ti}}+3.9 \times 4\right)=-1.2$

となるが，次の俎理由，凯ち

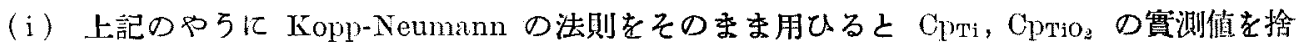
てて㝃みないことになる。

(ii) $\mathrm{Ti}_{2} \mathrm{O}_{3}$ と $\mathrm{Fe}_{2} \mathrm{O}_{3}$ とが絬晶梨が同じである.

(iii) $\mathrm{Fe}_{2} \mathrm{O}_{3}, \mathrm{Fe} の$ 比熱の貫测任は信肘していん.

上云ふ理由の下に，Ti， $\mathrm{Fe}_{2} \mathrm{O}_{3}, \mathrm{Fe}$ の分子熱の實测値を用ひて

を假定して計算した

$$
\mathrm{CpTi}, \mathrm{O}_{3}=2 \mathrm{Cp}_{\mathrm{Ti}}+\left(\mathrm{C}_{\mathrm{PF}_{2} \mathrm{O}_{3}}-2 \mathrm{C}_{\mathrm{PFe}}\right)
$$

c. Ti D原于㙰.

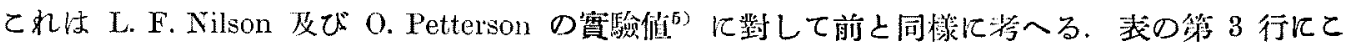
れを示す。

d. $\mathrm{FegO}_{3}$ の分子熟.

$$
\mathrm{CpFu}_{2} \mathrm{O}_{3}=14.13+0.0378 \mathrm{~T}^{63}
$$

$\left(298 \sim 633^{\circ} \mathrm{K}\right)$

e. $\mathrm{Fe} D$ 原子熱.

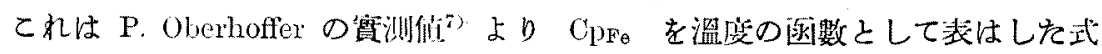

$$
\mathrm{C}_{1 \mathrm{Fo}}=2.336+0.009531 \mathrm{~T}
$$

を山ひた。

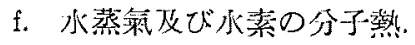

式（4) 及び (7)，(E)より

$$
\begin{aligned}
& \mathrm{H}_{2} \mathrm{O}(\mathrm{g}): \mathrm{Cp}_{\mathrm{p}}=8.81-0.0019 \mathrm{~T}+0.00000222 \mathrm{~T}^{2}{ }^{8)} \\
& \mathrm{H}_{2}: \mathrm{Cp}_{\mathrm{p}}=6.50+0.0009 \mathrm{~T}^{93}
\end{aligned}
$$

3) Mellor: 'Comprehensive Treatise on Inorganic and Theoretical Chemistry', VII, 37.4 4) A. Fucken: 'Handbuch der Experimental Physik,' VIII, 1 Teil, $200 . \quad 5)$ Mellor: 前揭, 15.6 6) Mellor: 前揭, XIII, 791. 7) P. Oberhoffer, Stahl u. Eisen, 47 (1927), 576. 8) Lewis \& Randall, 'Thermodynamics' (19:23), 103. 9) Lewis \& Randall, 'Thermodynamics' (1923), 104. 


$$
\begin{aligned}
& \Delta \mathrm{C}_{\mathrm{p}}=\left(\mathrm{C}_{\mathrm{p} \mathrm{Ti}_{2} \mathrm{O}_{3}}+\mathrm{Cp}_{\mathrm{H}_{2} \mathrm{O}}\right)-\left(2 \mathrm{Cp}_{\mathrm{TiO}}+\mathrm{Cp}_{3}\right) \\
& =2 \mathrm{CpTi}+-\mathrm{CpFe}_{2} \mathrm{O}_{3}-2 \mathrm{CpF}_{0}^{\prime}+\mathrm{CpH}_{2}-2 \mathrm{Cp}_{\mathrm{riO}_{3}}-\mathrm{CpH}_{2} \\
& =2 \mathrm{Cp}_{\mathrm{Ti}}-2 \mathrm{CpTi}_{2}+\left(11.768+0.0159 \mathrm{~T}+0.00000222 \mathrm{~T}^{2}\right) \cdots \cdots(12) \\
& \left(298 \sim 633^{\circ} \mathrm{K}\right)
\end{aligned}
$$

又 (6) に示したやらに $10 \pm 8 \sim 1256^{\circ} \mathrm{K}$ の閉の $4 \mathrm{Cp}$ の值は $9.72 \mathrm{cal}$ である. 今此れをその中脂

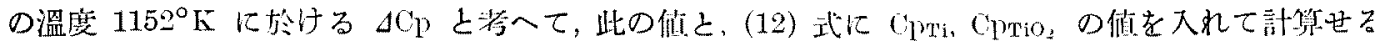
$\Delta \mathrm{Cp}$ の值とより最小自乘法により $424 \sim 1256^{\circ} \mathrm{K}$ の間の任意の溫度に於ける $\Delta \mathrm{C}_{1}$ の式を求めると

$$
\Delta \mathrm{Cp}=0.874+0.007712 \mathrm{~T} \quad \text { cal }
$$

となる。然るに

$$
\Delta \mathrm{Cp}=\mathrm{a}+\mathrm{bT}+\mathrm{cT}^{2}+\cdots \cdots \cdots \cdots \cdots
$$

とすれば

$$
\Delta \mathrm{H}_{\mathrm{T}}=\Delta \mathrm{H}_{0}+\mathrm{aT}+\frac{1}{2} \mathrm{bT}^{2}+\frac{1}{3}\left(\mathrm{~T}^{3}+\cdots \cdots \cdots \cdots \cdots\right.
$$

なる故

$$
\Delta \mathrm{H}_{\mathrm{T}^{\prime}}=\Delta \mathrm{H}_{0}+0.874 \mathrm{~T}+0.005856 \mathrm{~T}^{2}
$$

となる。然るに (3) 式より $\Delta \mathrm{H}_{1100}$ を計算し上式に入れ， $\mathrm{T}=1100$ と置いて $\Delta \mathrm{H}_{0}$ に就いて解くと $\Delta \mathrm{H}_{0}=4095 \mathrm{cal}$.

$$
\therefore \quad 2 \mathrm{TiO}_{2}+\mathrm{H}_{2}=\mathrm{Ti}_{2} \mathrm{O}_{3}+\mathrm{H}_{2} \mathrm{O} ; \Delta \mathrm{H}_{\mathrm{T}}=4095+0.874 \mathrm{~T}+0.008856 \mathrm{~T}^{2}
$$

今此の式が $298^{\circ} \mathrm{K}$ に於ても成立するものと考へると

$$
\Delta \mathrm{H}_{295}=4700 \text { al. }
$$

\section{III. 反應による遊離エネルギーの變化}

一般に

なる故

$$
\Delta \mathrm{F}=\Delta \mathrm{H}_{0}-\mathrm{aT} \ln \mathrm{T}-\frac{1}{2} \mathrm{l}, \mathrm{T}^{2}-\frac{1}{6} \mathrm{cT}^{3}-\cdots \cdots+\mathrm{IT} \cdot
$$

然るに一般に

$$
\Delta \mathrm{F}=4100-0.874 \times 2.3026 \mathrm{~T} \log \mathrm{T}-0.003856 \mathrm{~T}+\mathrm{IT} \text {. }
$$

$$
\Delta \mathrm{F}^{\circ}=-\mathrm{RT} \ln \mathrm{K}_{\mathrm{p}}
$$

である。今筥一報に於ける(9) 式

$$
\log \mathrm{Kp}=1.930-\frac{2754}{\mathrm{~T}}
$$

から, 例へば $1126^{\circ} \mathrm{K}$ に於ける最も碓からしい $\mathrm{Kp}$ の㑔を求めると

$$
\log K_{11: 0}=-0.51507
$$

となる. 此の值を(17) 式に大れると

$$
\Delta \mathrm{F}^{\urcorner}{ }_{1126}=2654 \mathrm{cal}
$$

依て此の $\Delta \mathrm{F}^{\circ}{ }_{1126}$ の值を（16）式に入れて I に就いて解くと

$$
I=10.1
$$

依て

$$
2 \mathrm{TiO}_{2}+\mathrm{H}_{2}=\mathrm{Ti}_{2} \mathrm{O}_{3}+\mathrm{H}_{2} \mathrm{O} ; \Delta \mathrm{F}^{\circ}=4095-2.0125 \mathrm{~T}^{\mathrm{T}} \log \mathrm{T}-0.003856 \mathrm{~T}^{2}+10.1 \mathrm{~T} \cdot
$$


今此の式が $298^{\circ} \mathrm{K}$ に於ても成立するものと考へると

$$
\begin{aligned}
2 \mathrm{TiO}_{2}+\mathrm{H}_{2}=\mathrm{Ti}_{2} \mathrm{O}_{3}+\mathrm{H}_{2} \mathrm{O} ; \quad \Delta \mathrm{F}^{\circ}{ }_{298} & =5280 \mathrm{cal} \\
\therefore \quad \Delta \mathrm{S}_{298} & =\frac{\Delta \mathrm{H}_{298}-\Delta \mathrm{F}^{\circ}{ }_{298}}{298} \\
& =1.95 \mathrm{cal} / \text { degree. }
\end{aligned}
$$

\section{IV. $\mathrm{Ti}_{2} \mathrm{O}_{3}+\frac{1}{2} \mathrm{O}_{2}=2 \mathrm{TiO}_{2}$ なる反應に於ける熱含量の \\ 變化及び遊離エネルギーの變化}

前述の如く $2 \mathrm{TiO}_{0}+\mathrm{H}_{2}=\mathrm{Ti}_{2} \mathrm{O}_{3}+\mathrm{H}_{2} \mathrm{O}$ なる反應に於ては，熱含量の變化及び逆離エネルギーの變 化は夫及，(14) 式及び (18) 式にて與へられるから

$$
\mathrm{Ti}_{2} \mathrm{O}_{3}+\mathrm{H}_{2} \mathrm{O}=2 \mathrm{TiC}_{2}+\mathrm{H}_{2}
$$

なる反應に向つては

$$
\begin{aligned}
& \mathrm{JH}=-4095-0.874 \mathrm{~T}-0.003856 \mathrm{~T}^{2} \ldots \ldots \ldots \ldots \ldots \ldots \ldots \ldots \\
& \lrcorner \mathrm{F}^{\circ}=-4095+2.0125 \mathrm{~T} \log \mathrm{T}+0.003856 \mathrm{~T}^{2}-10.1 \mathrm{~T}
\end{aligned}
$$

然るに

$$
\mathrm{H}_{2}+\frac{1}{2} \mathrm{O}_{\mathrm{g}}=\mathrm{H}_{2} \mathrm{O}(\mathrm{g})
$$

なる反應に於ては

$$
\begin{aligned}
& \Delta \mathrm{H}=-57425-0.94 \mathrm{~T}-0.00165 \mathrm{~T}^{2}+0.00000074 \mathrm{~T}^{3}{ }^{10} \\
& 1 \mathrm{~F}^{\circ}=-5742.5+0.94 \times 2.3026 \mathrm{~T} \log \mathrm{T}+0.00165 \mathrm{~T}^{2} \\
& -0.00000037 \mathrm{~T}^{3}+3.97 \mathrm{~T}^{113}
\end{aligned}
$$

從つて $(2)^{\prime}+(19)$ より $\mathrm{Ti}_{2} \mathrm{O}_{3}+\frac{1}{2} \mathrm{O}_{2}=2 \mathrm{TiO}_{2}$ なる故, 此の反㫘に對しては

$$
\begin{aligned}
& \mathrm{Ti}_{2} \mathrm{O}_{3}+\frac{1}{2} \mathrm{O}_{2}=2 \mathrm{TiO}_{2} ; \Delta \mathrm{H}=(14)^{\prime}+(20) \\
& =-61520-18.4 \mathrm{~T}-0.005506 \mathrm{~T}^{2} \\
& +0.00000074 \mathrm{~T}^{3} \\
& \Delta \mathrm{F}^{\circ}=(18)^{\prime}+(21) \\
& =-61520+4.1769 \mathrm{~T} \log \mathrm{T}+0.005506 \mathrm{~T}^{2} \\
& +0.00000037 \mathrm{~T}^{3}-6.13 \mathrm{~T} \\
& \therefore \quad \mathrm{Ti}_{2} \mathrm{O}_{3}+\frac{1}{2} \mathrm{O}_{2}=2 \mathrm{TiO}_{2} ; \quad \Delta \mathrm{H}_{298}=-62530 \mathrm{cal} \\
& \Delta \mathrm{F}^{\circ}{ }_{998}=-59770 \mathrm{cal} \\
& \Delta \mathrm{S}_{99}=-9.26 \mathrm{cal} / \text { degree. }
\end{aligned}
$$

\section{V. $2 \mathrm{Ti}+\frac{3}{2} \mathrm{O}_{2}=\mathrm{Ti}_{2} \mathrm{O}_{3} \quad$ なる反應に於ける熱含量の變化}

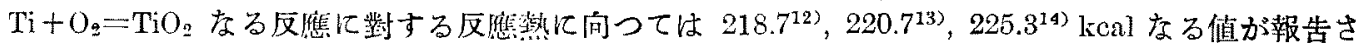

10) H. Ulich, 'Chemische Thermodynamik' (1930), 124, $\frac{1}{2} \mathrm{~W}_{(\mathrm{T})}$. 11) H. Ulich, 'Chemische Thermodynamik' (1930), 127, $\mathbf{K}_{(\mathrm{T})}$. 12) A. W. Roth, G. Becker, Zeits. phys. Chem. Bodensteinband (1931). 13) A. Sieverts, A. Gotta, Zeits. anorg. Chem., 199(1931), 384. 14) B. Neumann, C. Kröger, H. Kunz, Zeits. anorg. Chem., 218(1934), 384. 


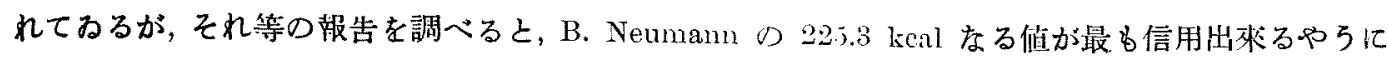
思はれるから $225.3 \mathrm{kcal}$ を採用するととにする。

然るに前篩の計賏より

$$
\begin{gathered}
2 \mathrm{TiO}_{2}=\mathrm{Ti}_{2} \mathrm{O}_{3}+\frac{1}{2} \mathrm{O}_{2}-62.5 \mathrm{kcal} \\
2 \mathrm{Ti}+2 \mathrm{O}_{2}=\mathrm{TiO}_{2}+225.3 \times 2 \mathrm{kcal} \\
\frac{2 \mathrm{Ti}+\frac{3}{2} \mathrm{O}_{2}=\mathrm{Ti}_{2} \mathrm{O}_{3}+388.07 \mathrm{kcal}}{2 \mathrm{Ti}+\mathrm{g}_{2}=\mathrm{Ti}_{2} \mathrm{O}_{3} ; \Delta \mathrm{H}_{998}=-388070 \mathrm{cal}}
\end{gathered}
$$

VI. $2 \mathrm{TiO}_{2}+\mathrm{CO}=\mathrm{Ti}_{2} \mathrm{O}_{3}+\mathrm{CO}_{2}$ なる反應に於ける遊離エネルギーの變化

$$
\begin{gathered}
2 \mathrm{CiO}_{2}+\mathrm{H}_{2}=\mathrm{Ti}_{2} \mathrm{O}_{3}+\mathrm{H}_{2} \mathrm{O} \\
\mathrm{OO}+\mathrm{H}_{2} \mathrm{O}=\mathrm{OO}_{2}+\mathrm{H}_{2} \\
2 \mathrm{TiO}_{2}+\mathrm{CO}=\mathrm{Ti}_{2} \mathrm{O}_{3}+\mathrm{CO}_{2}
\end{gathered}
$$

である。然るに $(24)$ なる反應に對しては

$$
\Delta \mathrm{F}^{\circ}=-10100+4.1677 \mathrm{~T} \log \mathrm{T}-0.00445^{2} \mathrm{~T}^{2}+0.00000068 \mathrm{~T}^{3}+0.54 \mathrm{~T}^{15)}
$$

故比(18)+(26)より

$$
\begin{aligned}
& 5 \mathrm{TiO}_{2}+\mathrm{CO}=\mathrm{Ti}_{2} \mathrm{O}_{3}+\mathrm{CO}_{2} ; \Delta \mathrm{F}^{\circ}=-6005+2.1552 \mathrm{~T} \log \mathrm{T}-0.008306 \mathrm{~T}^{2} \\
& +0.00000068 \mathrm{~T}^{\tilde{2}}+10.64 \mathrm{~T} \\
& \therefore \quad \Delta \mathrm{F}_{298}^{\circ}=-6220 \mathrm{cal} \text {. }
\end{aligned}
$$

\section{VII. $\mathrm{Ti}_{2} \mathrm{O}_{3} \quad$ の格子エネルギー}

1. 實䲆值.

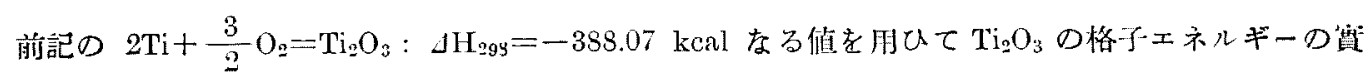

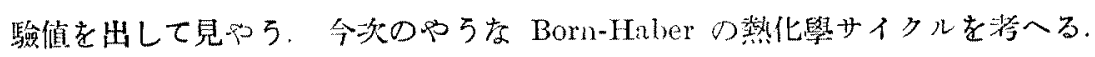

$$
\begin{aligned}
& 2(\mathrm{Ti})+3(\mathrm{O}) \stackrel{-2 \mathrm{I}}{\underset{-3 \mathrm{E}}{\longrightarrow}} 2\left(\mathrm{Ti}^{+++}\right)+3\left(\mathrm{O}^{--}\right) \\
& -2 \mathrm{~S} \uparrow-3 \mathrm{D} \quad \downarrow \mathrm{U}
\end{aligned}
$$

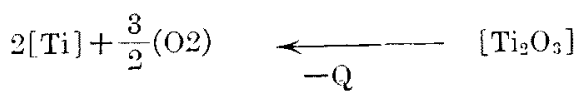

$$
\begin{aligned}
& {\left[\mathrm{Ti}_{3} \mathrm{O}_{3}\right]=2[\mathrm{Ti}]+\frac{3}{2} \mathrm{O}_{2} ; \Delta \mathrm{H}_{298}=\mathrm{Q} \text { ，生成熱 }} \\
& {[\mathrm{Ti}]=(\mathrm{Ti}) \quad ; \Delta \mathrm{H}_{993}=\mathrm{S} . \quad \text { 昇萿䓡 }}
\end{aligned}
$$

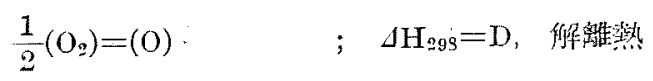

$$
\begin{aligned}
& (\mathrm{Ti})=\mathrm{Ti}^{+++}+3 \Theta \quad ; \quad \Delta \mathrm{H}=\mathrm{I}, \quad \text { 管離然 } \\
& (\mathrm{O})+2 \Theta=\left(0^{--}\right) \quad ; \Delta \mathrm{H}-\mathrm{E}, \quad \text { 電子親和力 } \\
& 2\left(\mathrm{Ti}^{+++}\right)+3\left(\mathrm{O}^{--}\right)=\mathrm{Ti}_{2} \quad ; \quad \Delta \mathrm{H}_{29 S}=-\mathrm{U},-(\text { 格于エェネキー }
\end{aligned}
$$

15) Lewis \& Randall, Thermodynamics (1923), 575. 
そらすれば肋かに

然るに

$$
\begin{aligned}
& \mathrm{U}=\mathrm{Q}+2 \mathrm{~S}+3 \mathrm{D}+3 \mathrm{I}+3 \mathrm{E} \\
& \mathrm{Q}=388.07 \quad \mathrm{kcal} \\
& \mathrm{D}=59.2 \quad \mathrm{kcal}{ }^{16)} \\
& \mathrm{I}=48.00 \times 23=1104.00 \quad \mathrm{kcal}^{17)} \\
& \mathrm{E}=168 . \quad \mathrm{kcal}^{18)}
\end{aligned}
$$

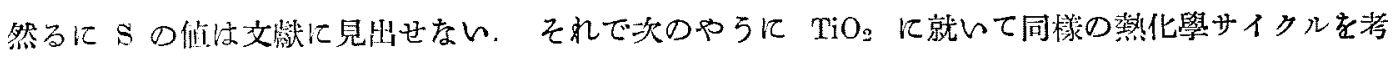
へ、それからSを部算した。

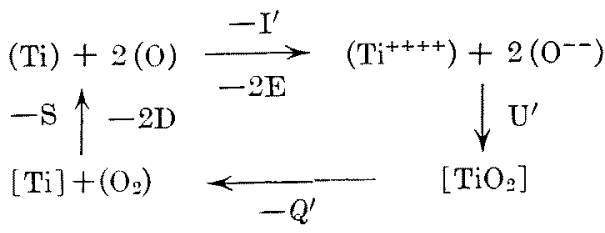

$$
\begin{aligned}
& \mathrm{S}=\mathrm{U}^{\prime}-\mathrm{Q}^{\prime}-2 \mathrm{D}-\mathrm{I}^{\prime}-2 \mathrm{E} \\
& \mathrm{Q}^{\prime}=225.3 \mathrm{kcal}{ }^{19)} \\
& \mathrm{I}^{\prime}=92.66 \times 23=2131.1 \mathrm{~s} \quad \mathrm{kcal}^{2^{03}}
\end{aligned}
$$

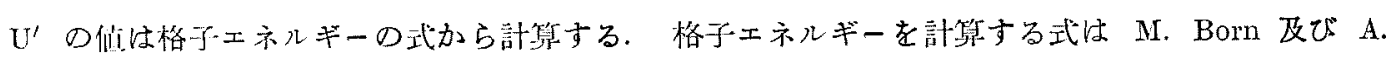
Lindé 等によつて提出されてるるが，此等は古典的な渃への下に發展したものであるが，最近 A. Kapustinsky"1, は L. Pauling 等の, 波動力學加ら出發して計算した結晶內のイオン間の距離を項に

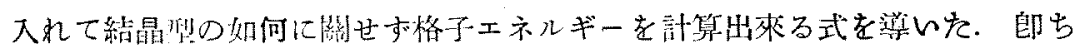

$$
\begin{aligned}
& \mathrm{U}_{0}=256.1 \frac{\eta_{1} \eta_{2} \Sigma \mathrm{n}}{\mathrm{r}_{\mathrm{A}}+\mathrm{r}_{\mathrm{K}}}
\end{aligned}
$$

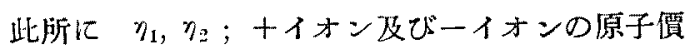

$$
\begin{aligned}
& \text { In ; 一D分子の中に在る原子の数 }
\end{aligned}
$$

Kapustinsky は此の式及び Bom の式から計相した格子ェネルギーの值と，蛽驗值より Born-Haber

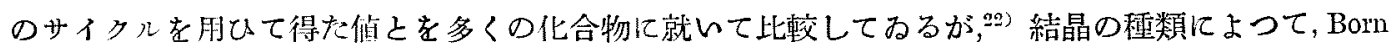

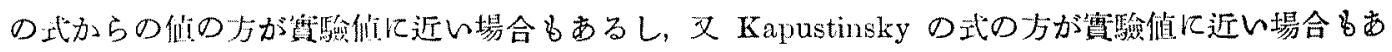

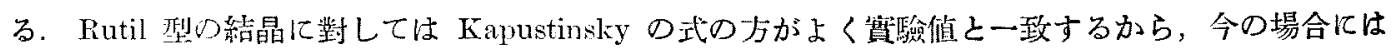
Kapusticky の式を探朋することにする. 從つて

$$
\begin{aligned}
& \eta_{1}=4, \quad \eta_{2}=2, \quad \quad \quad \quad n=3 \\
& r_{\mathrm{A}}+r_{K}=2.08 \AA^{233}
\end{aligned}
$$

なる故此机を上.式に入れるを

$$
\mathrm{U}_{0}=2955 \quad \mathrm{kcal} .
$$

然るに Born-Haber の熱化學サイクルから計算される格子ェネルギーは，氣體狀態のイオンから結

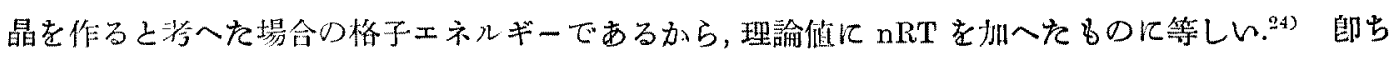

16) J. Sherman: Chem. Rev., 11 (1932), 143. 17) J. Sherman: Chem. Rev., $11(1932), 139 . \quad 18) \quad J$. Sherman: Chen. Rev., 11 (1932), 145. 19) B. Neumann: 前揭. 20) J. Sherman: 前揭, 139.21 ) A. Kapustinsky: Zeits. phys. Chem. (B), 22(1933), 357. 22) A. Kapustinsky, Zeits. phys. Chem. (B), 22(1933), 261. 23) L. Pauling: Journ Amer. Chem. 'Soc., 49(1927), 778. 24) J. Sberman: Chem. Rev, $11(1932), 147$. 
一般に

依て

$$
\mathrm{U}=\mathrm{U}_{0}+\mathrm{nRT} \quad \text { keal }
$$

$$
\begin{aligned}
\mathrm{U}^{\prime} & =\mathrm{U}_{0}+3 \times 0.002 \times 208 & & \mathrm{kcal} \\
& =\mathrm{U}_{0}+1.8 & & \mathrm{lical} \\
\therefore \quad \mathrm{U}^{\prime} & =2956.8 & & \mathrm{kcal}
\end{aligned}
$$

此の值及び Q，D，I，Eの任を（28）式に入れる己

2. 理論佔.

$$
\mathbf{U}=3569.51 \quad \mathrm{kcal}
$$

$\mathrm{Ti}_{2} \mathrm{O}_{3}$ は $\mathrm{A}\left[\mathrm{g} \mathrm{O}_{3}\right.$ 型の結晶であるが，若し單格子內の $\mathrm{Ti}$ 及び $\mathrm{O}$ の位舆が正碓にわかつてわるなら ば, Goldschmidt のイオン牛徑を朋ひ，Born の格子ェネルギーの式から計算出來るが，一般に $\mathrm{Al}_{2} \mathrm{O}_{3}$

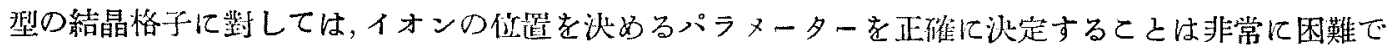

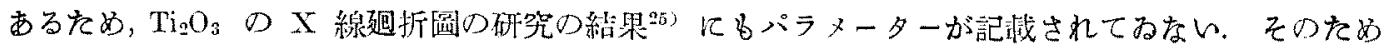
Born の式を棜ることは出來ない.今 Kapustinsky の式を朋ひると $\mathrm{Ti}^{+++}$イオンの有效牛徑を必要 とするが L. Pauling の論文にもこのイオン牛俓纯計算してない. それ故 $\mathrm{Ti}^{+++}$イオンの有效半徑の

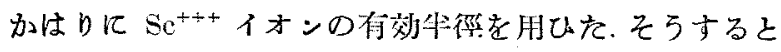

$$
\begin{array}{rlr}
\mathrm{U}_{0} & =3476.47 & \mathrm{kcal} \\
\mathrm{U} & =\mathrm{U}_{0} \times 5 \times 0.002 \times 298 & \mathrm{kcal} \\
& =3479.47 & \mathrm{kcal}
\end{array}
$$

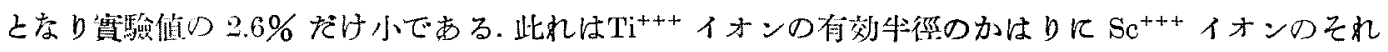

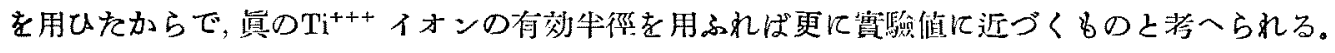

\section{VIII. 總括}

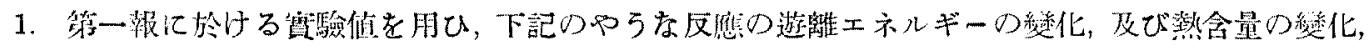
エントロピーの變化を計算した.

a. $2 \mathrm{TiO}_{2}+\mathrm{H}_{2}=\mathrm{Ti}_{2} \mathrm{O}_{3}+\mathrm{H}_{2} \mathrm{O}$;

$$
\begin{aligned}
& \Delta \mathrm{H}=4095+0.874 \mathrm{~T}+0.003856 \mathrm{~T}^{2} \\
& \Delta \mathrm{F}^{\circ}=4095-2.0125 \mathrm{~T} \log \mathrm{T}-0.003856 \mathrm{~T}^{2}+10.1 \mathrm{~T} \\
& \Delta \mathrm{H}_{208}=4700 \quad \mathrm{cal} \\
& \Delta \mathrm{F}_{998}^{\circ}=5280 \quad \mathrm{cal} \\
& \Delta \mathrm{S}_{299}=1.95 \quad \mathrm{cal} / \text { degree }
\end{aligned}
$$

1. $\mathrm{Ti}_{2} \mathrm{O}_{3}+\frac{1}{2} \mathrm{O}_{2}=2 \mathrm{TiO}_{2}$;

$$
\begin{aligned}
& \Delta \mathrm{H}=-61520-1.814 \mathrm{~T}-0.005506 \mathrm{~T}^{2}+0.00000074 \mathrm{~T}^{3} \\
& \Delta \mathrm{F}^{\circ}=-61520+4.1769 \mathrm{~T} \log \mathrm{T}+0.005506 \mathrm{~T}^{2} \\
& +0.00000037 \mathrm{~T}^{3}-6.13 \mathrm{~T} \\
& \Delta \mathrm{H}_{299}=-62530 \mathrm{cal} \\
& \Delta \mathrm{F}^{\circ}{ }_{298}=-59770 \mathrm{cal} \\
& \Delta \mathrm{S}_{998}=-9.26 \mathrm{cal} / \text { degree }
\end{aligned}
$$

25) P. P. Ewald, 'Strukturbericht.' Akademische Verlagsgesellschatt, Leipzig (1931). 


$$
\begin{aligned}
& \text { (. } 2 \mathrm{Ti}+\frac{3}{2} \mathrm{O}_{2}=\mathrm{Ti}_{2} \mathrm{O}_{3} ; \\
& \mathrm{JH}_{298}=-388070 \mathrm{cal} \\
& \text { d. } 2 \mathrm{TiO}_{2}+\mathrm{CO}=\mathrm{Ti}_{2} \mathrm{O}_{3}+\mathrm{CO}_{2} \text {; } \\
& \begin{array}{c}
\begin{array}{c}
\mathrm{J} \\
\mathrm{O}
\end{array}=-6005+2.1552 \mathrm{~T} \log \mathrm{T}-0.008306 \mathrm{~T}^{2} \\
+0.00000068 \mathrm{~T}^{3}+10.64 \mathrm{~T} \\
\Delta \mathrm{F}_{295}^{\circ}-6220 \mathrm{cal}
\end{array}
\end{aligned}
$$

உ. Ti の㫤華鼬計算し，Born-Haber の熱化學サイクルによつて $\mathrm{Ti}_{2} \mathrm{O}_{3}$ の格子ェネルギー を計算した。毁ち

$$
\mathrm{U}=3569.51 \mathrm{kcal}
$$

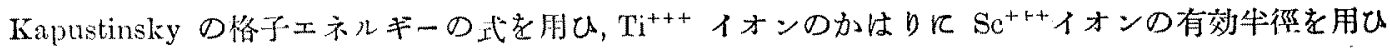

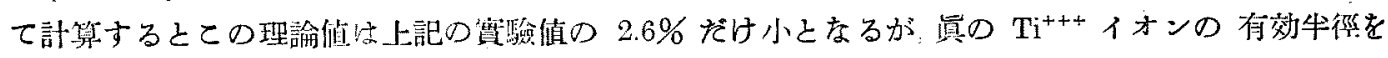

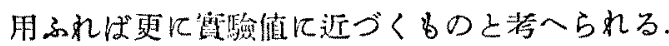

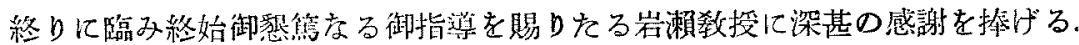

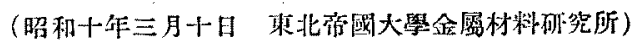

\section{五酸化ヴアナヂウムの解離 壓}

(昭和十年四月二日受領＼cjkstart昭科十年六月甘五日印刷)

那須 信 行

\section{I. 緒言}

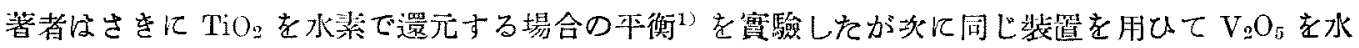
素で還元する場合の平衡を筫驗せんとしたが, $\mathrm{V}_{9} \mathrm{O}_{5}$ の試料を約 $200^{\circ}$ 亿熱してラングミニーアポンブ

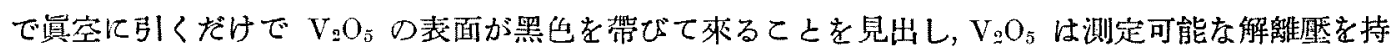

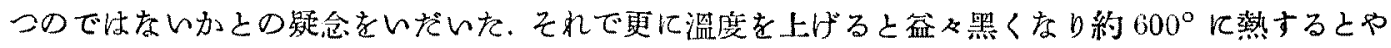

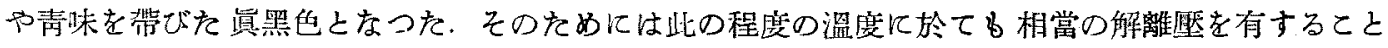

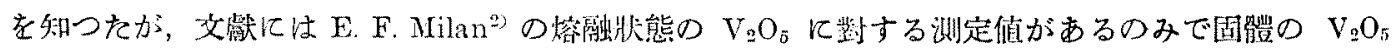

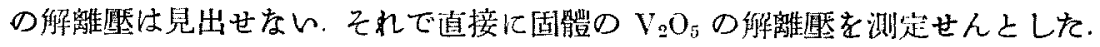

\section{1. 試}

料

\section{II. 實 驗及 び 結 果}

メルク製のヌタヴアナヂン酸アムモニウムを水に溶解し，その溶液にアルコホルを焩てメタヴ アナチン酸アムモニウムを再絬晶せしめ，乙れを二度繰返して純粹なメタヴアナヂン酸アムモニウ

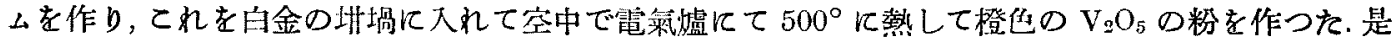
を瑪瑙の乳鈢でよくすり，粒を細くしたものを用ひた。

1) 那須: 本誌, $56(1935), 54 \%$.

2) E. F. Milan: J. phys. chem., 33 (1929), 498. 